\title{
AN UNUSUAL CASE OF RADIX PARAMOLARIS IN MANDIBULAR FIRST MOLAR: DIAGNOSED WITH SPIRAL CT FOLLOWED BY ROOT CANAL TREATMENT
}

Ashishkumar K. Patil ${ }^{1}$, Jayshree Vishwas ${ }^{2}$, Varsha Tambe ${ }^{3}$, Sarika Kolpe ${ }^{4}$

\section{HOW TO CITE THIS ARTICLE:}

Ashishkumar K. Patil, Jayshree Vishwas, Varsha Tambe, Sarika Kolpe. "An unusual case of radix paramolaris in mandibular first molar: diagnosed with spiral CT followed by root Canal Treatment". Journal of Evolution of Medical and Dental Sciences 2014; Vol. 3, Issue 01, January 06; Page: 226-229.

ABSTRACT: AIM-To diagnose radix paramolaris with the aid of spiral CT which often gets misdiagnosed in routine radiographic imaging to increase success rate of root canal treatment. SUMMARY: An additional mesio-buccal root, the radix paramolaris is major anatomical variant of the two rooted mandibular first molar. Awareness and understanding of this unusual root morphology contributes to the success of root canal therapy. This case report provides insight into the endodontic management of mandibular molar with radix paramolaris, with the aid of spiral computer tomography. The canals were shaped with hand protaper files and irrigated with 5.25\% sodium hyochlorite, $0.2 \% \mathrm{w} / \mathrm{v}$ of chlorhexidinegluconate and normal saline as the final irrigant. The canals were then obturated with gutta- percha and AH plus sealer. This case report shows an anatomic variation of internal morphology of the tooth and points out the importance of searching for additional canals and roots.

KEYWORDS: Radixparamolaris, spiral computed tomography, mandibular first molar.

INTRODUCTION: An awareness and understanding of the presence of unusual root canal morphology can contribute to the successful outcome of root canal treatment. It is known that the mandibular first molar can display several anatomical variations. Commonly the mesial root has two root canals, ending in two distinct apical foramina. Sometimes these merge together at the root tip to end in one foramen. The distal root typically has one kidney- shaped root canal, although if the orifice is particularly narrow and round, a second distal canal may be present. The number of roots may also vary 1 .

The prevalence of these three-rooted mandibular first molars appears to be less than $3 \%$ in African populations, not to exceed $4.2 \%$ in Caucasians, to be less than $5 \%$ in Eurasian and Asian populations ${ }^{2}$, and to be higher than $5 \%$ (even up to $40 \%$ ) in populations with Mongolian traits ${ }^{3}$ and $5.97 \%$ in Indian population. An additional third root, first mentioned in the literature by Carabelli (1844), is called the radix entomolaris (RE) when it is present lingually and paramolaris when it is present buccally4.The study of root and canal anatomy has endodontic (Vertucci 1984) and anthropological (Tratman 1950, Dahlberg 1965, Walker 1988a, b) significance ${ }^{5}$. It is important to be familiar with variations in tooth anatomy. With advent of Dental CT and Cone beam computed tomography (СBCT) the shortcomings of conventional imaging are overcome as they provide accurate and specific information. Dental CT with dedicated post scanning image evaluation software used for the teeth and the jaw creates panoramic and paraxial views of the upper and lower

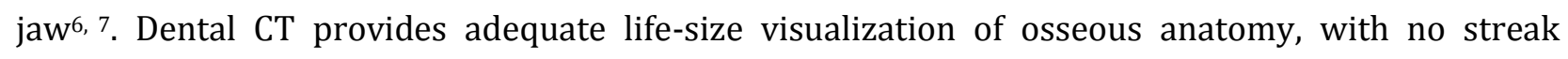
artifacts of restorative material and a lower radiation dose compared with conventional CT. 
CASE REPORT: A 25-yrs male reported with the chief complaint of pain in the left mandidular tooth to the Amrutvahini hospital, Sangamner. On clinical examination the tooth was grossly decayed and radiographically the unusual root pattern seen with mesial root Fig A. To ascertain this complex root anatomy spiral CT was planned. The spiral CT was performed at Sai Baba Hospital Shirdi. The CT scan machine used was Seimens Somatom Sensation 64 which had multidetector technology with 32 detectors and 64 data channels. Scan direction was caudocranial beginning with the mandible base and extends to include the alveolar crest. Slice thickness of the images was adjusted to $0.5 \mathrm{~mm}$ with slice interval of $2 \mathrm{~mm}$. Tube current is $90 \mathrm{mAs}$, tube voltage is 120 , and table pitch is 0.9. Multiplanar reconstructions based on the dental CT protocol were obtained in the orthoradial and panoramic plane by using a dental software package (Syngo Dental CT 2006 A-W VB20B-W) on a workstation Fig. B with buccal view and Fig.C with lingual view ${ }^{8,9}$. The $3 \mathrm{D}$ reconstruction shows an additional root mesio-buccally with unusual morphology ${ }^{10}$. After application of rubber dam, access was gained to the pulp chamber fig D. The coronal necrotic pulp tissue was removed and the chamber irrigated with $5.25 \%$ sodium hypochlorite solution (Comet India ltd). On close inspection of the pulp chamber, four distinct canal orifices, two mesial \& two distal, were found. Initial negotiation of the root canals was performed with an ISO 15 No. K file ${ }^{11}$. The different access inclinations between the two mesial canals,indicated the presence of two separate mesial roots. The lengths of these canals were measured radiographically and verified using apex locator (Dentaport, J Morita)Fig E. The canals were cleaned with sodium hypochlorite solution (5.25\%) and Glyde (DentsplyMaillefer), and shaped withhand ProTaper instrument no. F2 (Dentsply Maillefer).All canals were filled with gutta-percha and $\mathrm{AH}$ plus sealer ${ }^{12}$. Post endodontic restoration done with composite restorative material Fig F.

DISCUSSION: The etiology behind the formation of the radix paramolaris and entomolaris is still unclear. In dysmorphic, supernumerary roots, its formation could be related to external factors during odontogenesis, or to penetrance of an atavistic gene or polygenetic system ${ }^{13}$. The presence of the Radix paramolaris or the Radix entomolaris has clinical implications in endodontic treatment. Radiograph and interpretation of particular marks or characteristics, such as an unclear view or outline of the mesial root contour or the root canal,can indicate the presence of a 'hidden' Radix paramolaris ${ }^{14}$.Slowley (1974) has demonstrated how difficult it is to detect extra roots, let alone extra canals. On the contrary, completing a thorough radiographic study of the involved tooth with exposure from three different horizontal projections, the standard buccal-to-lingual projection, $20^{\circ}$ from the mesial, and $20^{\circ}$ from the distal reveals the basic information regarding the anatomy of the tooth in order to perform endodontic treatment (Ingle et al. 2002).

To reveal the Radix paramolaris, a second radiograph should be taken from a more mesial or distal angle (20 degrees). This way an accurate diagnosis can be made. Dental CT has about eight times higher resolution than the medical CT. Therefore, this device is thought to be useful for the examination and diagnosis of hard tissues of the maxillofacial region including teeth, alveolar bone, and the jaws. Intraoral radiographs are a two-dimensional imaging modality of a three-dimensional structure ${ }^{15,16 .}$

Hence anatomy in the third dimension cannot be assessed on radiographs. Because root canals tend to lie one behind the other in buccolingual plane, they get superimposed onto each other on periapical, panoramic radiographs and easily go undetected.Predictably successful root canal treatment is dependent on following the basic principles: access, cleansing and shaping, and 


\section{CASE REPORT}

obturation of the entire root canal system. These principles have evolved from clinical concepts established through clinical practice and basic research ${ }^{17,18}$.

CONCLUSION: Preoperative periapical radiographs exposed at two different horizontal angles are required to identify these additional roots. Knowledge of the location of the additional root and its root canal orifice will result in a modified opening cavity with extension to the mesiobuccal. The morphological variations of the Radix paramolaris in terms of root inclination and root canal curvature demand a careful and adapted clinical approach to avoid or overcome procedural errors during endodontic therapy.

\section{REFERENCES:}

1. Ahmed HA, Abu-bakr NH, Yahia NA, Ibrahim YE. Root and canal morphology of permanent mandibular molars in a Sudanese population. International Endodontic Journal 2007;40:76671.

2. Al-Qudah AA, Awawdeh LA. Root canal morphology of mandibular incisors in Jordanian population. International Endodontic Journal 2006; 39: 1-5.

3. Awawdeh LA, Al-Qudah AA. Root form and canal morphology of mandibular premolars in a Jordanian population. International Endodontic Journal 2008; 41: 240-8.

4. Calberson FL, De Moor RJ, Deroose CA. The radix entomolaris and paramolaris: clinical approach in endodontics. Journal of Endodontics 2007;33(1):58-63.

5. Carlsen O, Alexandersen V. Radix paramolaris in permanent mandibular molars: identification and morphology. European Journal of Oral Sciences 1991; 99 (3): 189-95.

6. De Moor RJ, Deroose CA, Calberon FL. The radix entomolaris in mandibular first molars: an endodontic challenge. International Endodontic Journal 2004; 37: 789-99.

7. Ferraz JAB, Pécora JD. Three-rooted mandibular molars in patients of Mongolian, Caucasian and Negro origin. Braz Dent J 1993; 3(2):113-7.

8. Gulabivala K, Aung TH, Ng Y-L, Alavi A. Root and canal morphology of Burmese mandibular molars. International Endodontic Journal 2001; 34: 359-70.

9. Gulabivala K, Opasanon A, Ng Y-L, Alavi A. Root and canal morphology of Thai mandibular molars. International Endodontic Journal2002;35:56-62.

10. JayapradaReddy.The Radix Entomolaris - an endodontic challenge:casereports.Annals and Essences of Dentistry 2001; 2 ( 3):23-8.

11. JogikalmatKrithikadatta, JojoKottoor, ChellaswamySavarimalaiKarumaran, GunaseelanRajan. Mandibular First Molar Having an Unusual Mesial Root Canal Morphology with Contradictory Cone-Beam Computed Tomography Findings: A Case Report. Journal of Endodontics 2010; 36:1712-16.

12. Mannocci F, Peru M, Sherriff M, Cook R, Pitt Ford TR. The isthmuses of the mesial root of mandibular molars: a micro-computed tomographic study. International Endodontic Journal 2005;38: 558-63.

13. Ming-Gene Tu, Chi-Cheng Tsai, Ming-JiaJou, Wil-Lie Chen. Prevalence of Three-rooted Mandibular First Molars among Taiwanese Individuals. Journal of Endodontics 2007;33:116366.

14. Sert S, Aslanalp V, Tanalp J. Investigationof the root canal configurations of mandibular permanent teeth in the Turkishpopulation. IntEndod J. 2004; 37: 49-99. 
15. Vertucci FJ. Root canal anatomy of the human permanent teeth. Oral Surgery, Oral Medicine, Oral Pathology1984;58(5):589-99.

16. Walker RT. Root form and canal anatomy of mandibular first molars in a southern Chinese population. Endodontics and Dental Traumatology 1988; 4:19-21.

17. Weine FS. Initiating Endodontic treatment. Endodontic Therapy 2004; 6: 104-63.

18. Wasti F, Shearer AC, Wilson NHF. Root canal systems ofthe mandibular andmaxillary first permanent molar teeth ofsouth Asian Pakistanis. IntEndod J. 2001;34:263 -6.

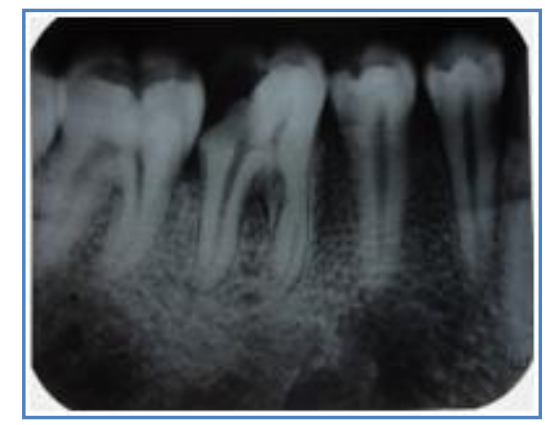

a

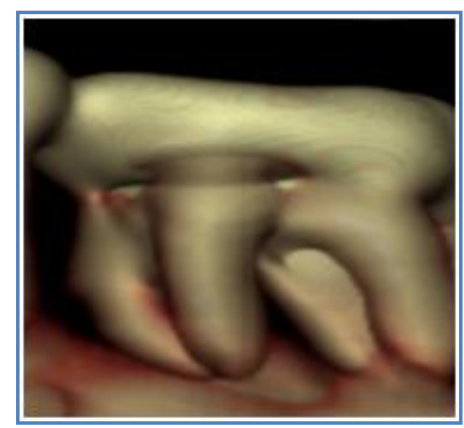

b

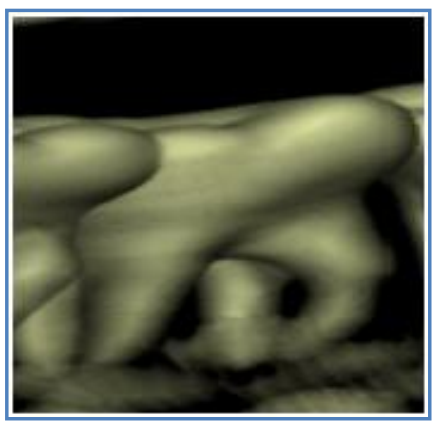

C

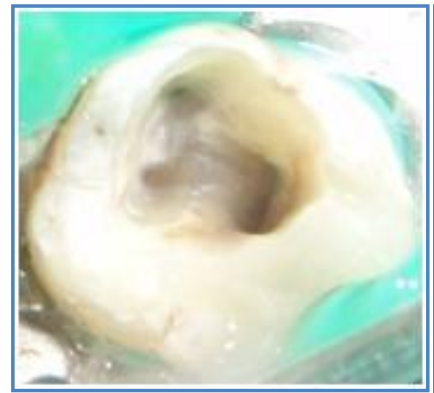

d

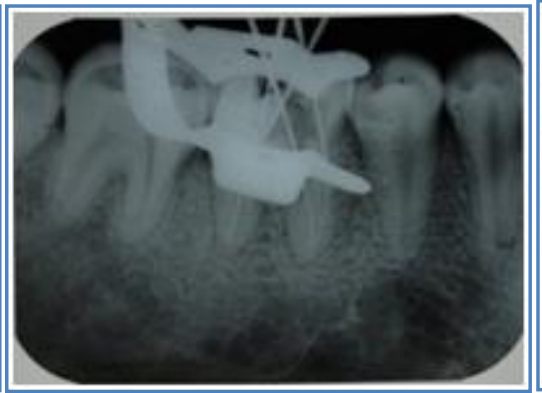

e

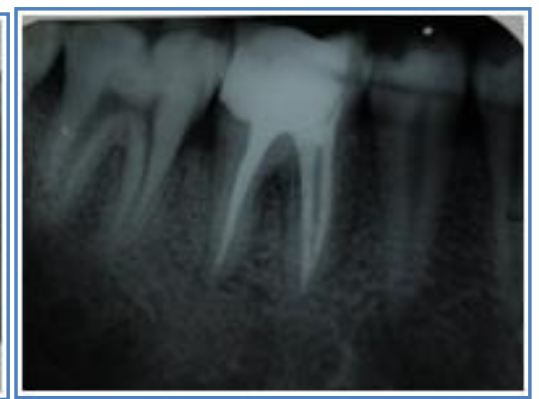

f

\section{AUTHORS:}

1. Ashishkumar K. Patil

2. Jayshree Vishwas

3. Varsha Tambe

4. Sarika Kolpe

\section{PARTICULARS OF CONTRIBUTORS:}

1. Senior Lecturer, Department of Conservative Dentistry and Endodontics, SMBT Dental College, Sangamner.

2. Senior Lecturer, Department of Conservative Dentistry and Endodontics, SMBT Dental College, Sangamner.

3. Post Graduate Student, Department of Conservative Dentistry and Endodontics, SMBT Dental College, Sangamner.
4. Tutor, Department of Conservative Dentistry and Endodontics, SMBT Dental College, Sangamner.

\section{NAME ADDRESS EMAIL ID OF THE CORRESPONDING AUTHOR:}

Dr.Ashishkumar K. Patil, JarhadPatil Dental Clinic, Opp. Sangamner Merchant Bank, Navin Nagar Road, Sangamner - 422605.

Email-dr.ashishpatil551@gmail.com

Date of Submission: 21/11/2013.

Date of Peer Review: 22/11/2013.

Date of Acceptance: 05/12/2013.

Date of Publishing: 06/01/2014 